\title{
THE RELATIONSHIP BETWEEN ANXIETY AND PERFORMANCE IN A STATISTICS CLASS
}

\author{
SUSAN E. MASON AND ELIZABETH M. REID
}

\begin{abstract}
Many students experience anxiety when taking a required statistics course. As high levels of anxiety may interfere with performance, it is desirable to identify and control factors shown to affect student anxiety. The purpose of our research was to examine the relationship between anxiety and performance and to determine which aspects of course structure have the greatest effects on student anxiety levels. In a series of four studies we found self-reported anxiety levels to be negatively correlated with both grade expectations and final course grades. Students attributed decreases in anxiety levels to several factors, including class exercises and class atmosphere.
\end{abstract}

\section{INTRODUCTION}

Student performance has been shown to be affected by the student's level of anxiety $[1,4,6]$. Though some anxiety may heighten motivation and attention, thus strengthening performance, high levels of anxiety are likely to compromise a student's confidence and concentration, interfering with the student's ability to perform. People often experience high levels of anxiety when taking statistics courses or other mathematics-based courses [9]. The individual student's level of anxiety will depend on characteristics of the student, such as personality [18], background $[2,5,11]$, and skill level $[7,12,15]$, as well as characteristics of the course, such as the textbook, the professor, and the structure of the course.

Relatively few studies have examined characteristics of the course and their effects on student anxiety. In one study, Pan and Tang [16] used a questionnaire to assess anxiety levels before and after a statistics course for graduate students in the social sciences. The researchers found a reduction in anxiety level which they attributed to application-oriented teaching methods and the instructors' attention to the students' anxiety. In another study, Pan and Tang [17] used the focus group method to determine what factors contributed to statistics anxiety in a group of social science graduate students. The students indicated that having several small quizzes was preferable to having a comprehensive exam. The students mentioned two other factors related to course structure. They valued practical exercises and the flexible office hours of instructors and teaching assistants.

$M S C$ (2010): primary 97C70.

Keywords: statistics education, student anxiety, course support. 
The purpose of our research was to determine, in an undergraduate statistics course, which aspects of course structure have the greatest effects on student anxiety levels, and to determine whether the effects are greater early or later in the semester.

\section{STUdy 1}

\subsection{Study 1 methodology}

A total of 43 undergraduate students served as participants in this study. The students were from three sections of a required statistics course, all taught by the same professor.

We structured the statistics course to incorporate a number of aspects hypothesized to minimize student anxiety. For example, to decrease the grade value of any one assignment, homework assignments and tests began early in the semester and were given frequently. There were 18 homework assignments and eight tests in all. To provide additional support and facilitate communication, both within and across course sections, we distributed a list of student names and e-mail addresses to the class, and a student assistant was assigned to the course. Students were encouraged to contact each other to work on homework assignments and study for tests. They were also encouraged to meet with the student assistant for tutoring and homework assistance. Other factors that we examined were rapid feedback on homework and tests, and the frequent use of in-class exercises. Graded materials were returned and reviewed the next class period after they were due, so that students had feedback on their work before moving on. In-class exercises were practiced each day, so that students could gain experience on new procedures while the professor was available for support and guidance.

We assessed student anxiety about the course at three points in the semester. The first assessment was on the first day of class, after the professor had reviewed the syllabus. The second assessment took place in the third week of the semester, by which time the students had completed two homework assignments and a test. The third and final assessment occurred in the final week of the classes. At each of the three assessments students were asked to rate their anxiety level on a scale from 1 (not at all anxious) to 10 (very anxious). On the first day, we also asked students to predict the course grade they would earn. In the third week, and in the final week, students completed a questionnaire about how aspects of the course had affected their anxiety level since the beginning of the semester. Students judged, on a 5-point scale, whether nine different aspects of the course lowered their anxiety (rated 1 or 2 on the scale), raised their anxiety (rated 4 or 5 on the scale), or had no effect on their anxiety level (rated 3 on the scale).

\subsection{Study 1 results and discussion}

Pearson correlations were conducted to determine the relationship between a student's prediction of the final course grade and the student's actual grade. Final course grades were positively correlated with predicted course grades, $r(41)=.31$, $p<.05$. A Pearson correlation between anxiety levels and final course grades revealed a negative relationship, $r(41)=-.34, p<.05$. Students with high anxiety 
levels tended to have low grades, and those with low anxiety levels tended to have high grades.

Overall, students reported a drop in anxiety level from the beginning of the semester $(M=5.74)$ to the third week of the semester $(M=4.74), t(41)=3.20$, $p<.01$. This analysis was based on 42 students, rather than the total of 43 students, as one student was absent on the day of the second assessment. There was no further drop in anxiety level from the third week of the semester to the final week of the semester.

At the three-week assessment, students evaluated various course characteristics (see Table 1). Of all the factors considered, students reported that class exercises put them most at ease. As predicted, a number of other course characteristics were reported to reduce anxiety. The mean ratings for early homework assignments, frequent homework assignments, homework grades, and the student e-mail list indicate that these aspects of the course structure also led to decreases in anxiety. The one finding that did not follow expectations was the effect of test grades; test grades were associated with a slight increase in anxiety. The two remaining factors, early tests and frequency of tests, were associated with slight decreases in anxiety, but those means did not differ significantly from the mean associated with test grades.

The pattern of questionnaire responses in the final week was similar to the pattern of responses in the third week (see Table 1). Students reported that most of the course characteristics lowered anxiety levels more at the end of the semester than they had by the third week of the semester. The only course characteristics not associated with greater anxiety reductions at the end of the semester were the student e-mail list and the student assistant (see Table 1).

Table 1. Effect of Course Characteristic on Anxiety Rating $(1=$ lowered anxiety to $5=$ raised anxiety).

\begin{tabular}{llllll}
\hline & \multicolumn{2}{l}{ Third Week } & & \multicolumn{2}{c}{ Final Week } \\
\cline { 2 - 3 } \cline { 5 - 6 } Course Characteristic & $M$ & $S D$ & & $M$ & $S D$ \\
\hline Class Exercises & 1.74 & 1.08 & & 1.57 & 0.77 \\
Early Homework & 2.21 & 0.95 & & 2.02 & 1.07 \\
Frequent Homework & 2.33 & 1.18 & & 1.95 & 1.08 \\
Homework Grades & 2.45 & 1.29 & & 2.35 & 1.38 \\
Early Tests & 2.81 & 1.23 & & 2.57 & 1.37 \\
Frequent Tests & 2.57 & 1.21 & & 2.30 & 1.51 \\
Test Grades & 3.12 & 1.27 & & 2.86 & 1.62 \\
E-mail List & 2.36 & 0.82 & & 2.62 & 0.72 \\
Student Assistant & 2.52 & 0.80 & & 2.57 & 0.65 \\
\hline
\end{tabular}

In addition to the specific questions that we posed to the students, we gave the students the opportunity to report other aspects of the course that affected their anxiety levels. One issue, the lack of clarity of the instructions in the workbook, led to more worry on the part of all four students who mentioned it. The other 
issue, lecture format, increased the anxiety levels of two students and lowered the anxiety levels of two students.

\section{STUdy 2}

\subsection{Study 2 methodology}

In Study 2 we assessed the relationship between confidence and competence in a statistics class. A total of 43 university students enrolled in three sections of a statistics course participated in this study. All three sections of the course were taught by the same professor.

On the first day of the semester, the students were asked what grade they expected to receive in the course. They were also asked to rate their anxiety about the course, on a scale from 1 (not at all anxious) to 10 (very anxious). At the end of the semester, the students' grades were compared with their grade expectations. In addition, we assessed the value of self-reported anxiety level, and expected grade, as predictors of the student's final course grade.

\subsection{Study 2 results and discussion}

On average, students expected to earn a $\mathrm{B}+$ grade in the course $(M=3.51)$. Selfreported anxiety levels tended to be moderate $(M=5.77)$, though ratings ranged from a low of one to a high of ten. Final course grades for these students averaged $\mathrm{C}+(M=2.55)$, a letter grade lower than the students expected. A multiple linear regression was calculated to predict students' grades based on their anxiety levels and expected grades. A significant regression equation was found $(F(2,40)=4.20$, $p<.05)$, with an $R^{2}$ of .17 . A student's predicted grade is equal to $-.16-$ .14 (anxiety) + (expected grade), where anxiety is rated from 1 (low) to 10 (high) and expected grade is coded as $1=\mathrm{D}, 2=\mathrm{C}, 3=\mathrm{B}$, and $4=\mathrm{A}$.

As predicted, anxiety levels at the start of the semester were negatively correlated with course grades. Those students who expressed the most anxiety about the statistics class were the most likely to perform poorly. Those with lower levels of anxiety at the start of the semester tended to have higher grades for the course. Despite the fact that students expressed anxiety about the course, they expected that they would perform well. As hypothesized, the students were not realistic about their expectations. Their actual grades were, on average, a letter grade lower than they had anticipated. These results are consistent with the results of Dunning et al. [8], Hodges et al. [10], and Kruger and Dunning [13]. Using different tasks and samples from different populations, the general finding held true: individuals failed to recognize their own weaknesses, which led to inflated self-assessments.

\section{STUdy 3}

\subsection{Study 3 methodology}

Study 3 was designed to further explore the relationship between anxiety and grade expectations, and to test the idea that self-reported anxiety drops as early as the 
first day of class. The participants were 55 undergraduate students enrolled in three sections of a required statistics course, all taught by the same professor.

At the beginning of class, on the first day of the semester, the students were asked to write down the grade they expected to receive in the course. In addition, each student was asked to rate his or her anxiety level, from 1 (not at all anxious) to 10 (very anxious). The professor reviewed the course syllabus and introduced the basic topics to be covered in the course. At the end of the first class period, the students were again asked to report what grade they expected to receive in the course and rate their anxiety levels. After 7 weeks of class, during which time there were 8 graded homework assignments and 3 tests, the students were asked a third time to report their expected grades and anxiety levels.

\subsection{Study 3 results and discussion}

A paired samples $t$-test revealed a significant drop between self-reported anxiety at the start of the first class $(M=6.03)$ and self-reported anxiety at the end of the first class $(M=5.21), t(54)=3.91, p<.001$. However, further changes from the end of the first class $(M=5.33)$ to the seventh week of the semester $(M=5.51)$ were statistically insignificant, $t(47)=-.65, p>.05$. Grade expectations were negatively correlated with anxiety at the start of class, but they did not change during the first class when anxiety levels dropped.

Bartsch [3] reported on an activity designed to improve students' attitudes toward statistics. He assessed attitude at the beginning and end of the first day of class. Between the two assessments, he involved students in activities that demonstrated various statistical concepts. An improvement in attitude was attributed to the assigned activities. Our finding of reduced anxiety following a simple review of the syllabus and basic course content suggests that a specific activity may not be necessary. Exposure to the professor, exposure to other students, and a review of the course requirements may be sufficient to reduce anxiety and improve attitudes toward statistics. It is interesting to note that an evaluation after seven weeks showed no further improvement.

\section{STUDY 4}

\subsection{Study 4 methodology}

Study 4 was designed as a replication and extension of Study 3. The participants were 52 undergraduate students enrolled in three sections of a required statistics course. All three sections were taught by the same professor. At the beginning of class, on the first day of the semester, the students were asked to write down the grade they expected to receive in the course. In addition, each student was asked to rate his or her anxiety level, from 1 (not at all anxious) to 10 (very anxious). The professor reviewed the course syllabus and introduced the basic topics to be covered in the course. At the end of the first class period, the students were again asked to report what grade they expected to receive in the course and rate their anxiety levels. If their anxiety levels had changed from the start of class, they were asked to indicate the reason for the change. 


\subsection{Study 4 results and discussion}

A paired samples $t$-test revealed a significant drop in self-reported anxiety, from the start of the first class $(M=5.64)$ to the end of the first class $(M=5.02)$, $t(51)=3.52, p<.001$. Though anxiety levels dropped, grade expectations did not change during the first class meeting. These results are consistent with the findings of Study 3.

In Study 4, we used three categories to classify the reasons students gave for changes in their anxiety levels: mathematics experience, class atmosphere, and psychology experience. A chi-square test of independence was calculated comparing the frequency of each type of response for students whose anxiety rose, dropped, or remained constant. A significant interaction was found $\left(\chi^{2}(6)=12.59, p<.05\right)$. Those who reported drops in their anxiety levels were more likely to cite class atmosphere than experience as the reason, while the few who reported increases in anxiety were more likely to cite previous mathematics experience.

\section{General Discussion And COnClusions}

Our findings are consistent with previous work showing a negative correlation between anxiety and performance in statistics courses. Higher grades were earned by students who reported lower levels of anxiety. Final course grades were also correlated, though positively, with students' predictions of the grades they would earn. Those who expected to perform well, performed well.

In our first study we found that self-reported anxiety levels decreased in the first three weeks of the semester and then remained low. When we asked students to assess how course structure affected their anxiety levels, they reported that several factors helped to reduce their anxiety. Of all of the factors considered, class exercises emerged as the most important factor. The implication is that frequent practice on statistical procedures can not only build skills, but increase confidence and decrease anxiety.

One unexpected finding was that test grades did not lower anxiety levels at the three-week assessment. In conversations, a number of students reported having expected higher grades than they received on the first test. It is understandable, then, that their concerns about the course increased some as a result of what they perceived as disappointing feedback. Another somewhat surprising finding was that the student e-mail list and the student assistant did not lead to an additional drop in anxiety from the third week of the semester to the final week. A drop resulted with every other factor. One possible explanation is that the students did not use these supports enough to continue benefiting from them throughout the semester. Perhaps the results would have been different if we had required study groups or tutoring.

Our second study examined the relationship between self-reported anxiety, expected grades and actual performance. While students predicted high grades, overestimating their ability, anxiety levels revealed a lack of confidence that was negatively correlated with final grades.

In our third study we found a reduction in anxiety on the first day of class, following a simple review of the syllabus and basic course content. This suggests that 
exposure to the professor, exposure to other students, and a review of the course requirements may be sufficient to reduce anxiety and improve attitudes towards statistics. Our fourth study replicated the results of the third study and assessed the reasons why anxiety levels can change significantly on the first day of class. Although some students attributed the change in their anxiety levels to previous experience with mathematics, the large majority cited the class atmosphere as the important factor.

Future research should consider the extent to which our findings are unique to statistics courses. In one comparison of similarly structured statistics and psychology courses, Mason and Grenier [14] found that students in both courses reported a drop in anxiety from the first day to the third week of the semester. From the third week to the tenth week, statistics students showed a further drop in anxiety, while psychology students showed a slight increase in anxiety. The two groups differed in their overall anxiety levels and they attributed changes in their anxiety levels to different factors. Most notable was the fact that frequent homework assignments decreased the anxiety levels of statistics students, but caused a slight increase in the anxiety levels of psychology students. Both groups reported that, of the nine course characteristics considered, having homework assignments early in the semester was what put them most at ease.

One limitation of our research is that it relies on self-report data. It may be difficult for students to accurately assess and report changes in their anxiety levels, and to attribute those changes to specific factors. Another limitation of our research is that we looked at correlations; we did not run an experiment with a control condition. We found that anxiety was negatively correlated with performance, but we cannot conclude from our data that high levels of anxiety cause poor performance. Nor can we definitively state that the course structure we provided reduced anxiety levels; we can only conclude that students reported reduced anxiety, which they attributed to aspects of the course structure and class atmosphere. Finally, though our focus was on course structure and anxiety, there are other factors that may have influenced the results. The textbook, characteristics of the students and the professor may all affect anxiety levels and may interact with aspects of course structure.

The results of our research indicate that students are affected by the structure of a statistics course. We identified several factors that may increase or decrease student anxiety levels and, presumably, student performance. We demonstrated that anxiety levels may change at any point in the semester, including the first day of class. Based on our findings, we recommend that every effort be made to provide a positive class atmosphere from day one, maximum support throughout the semester, and frequent feedback. We further recommend that instructors assess anxiety levels and the effectiveness of the course structure early in the term. By monitoring anxiety levels, as well as grades, the instructor may consider midterm modifications that could improve performance.

\section{References}

[1] M. H. Ashcraft and E. P. Kirk, The relationship among working memory, math anxiety, and performance, Journal of Experimental Psychology, General 130 (2001), 224-237. 
[2] M. Baloğlu, Individual differences in statistics anxiety among college students, Personality and Individual Differences 34 (2003), 855-865.

[3] R. A. Bartsch, Improving attitudes toward statistics in the first class, Teaching of Psychology 33 (2006), 197-198.

[4] S. L. Beilock and E. A. Maloney, Math anxiety: A factor in math achievement not to be ignored, Policy Insights from the Behavioral and Brain Sciences 2 (2015), 4-12.

[5] S. L. Beilock and D. T. Williangham, Math anxiety: Can teachers help students reduce it?, American Educator 38 (2014), 28-32.

[6] G. L. Cates and K. N. Rhymes, Examining the relationship between mathematics anxiety and mathematics performance: An instructional hierarchy perspective, Journal of Behavioral Education 12 (2003), 23-34.

[7] F. F. Conners, S. M. McCown and B. Roskos-Ewoldsen, Unique challenges in teaching undergraduate statistics, Teaching of Psychology 25 (1998), 40-42.

[8] D. Dunning, K. Johnson, J. Ehrlinger and J. Kruger, Why people fail to recognize their own incompetence, Current Directions in Psychological Science 12 (2003), 83-97.

[9] R. Hembree, The nature, effects, and relief of mathematics anxiety, Journal for Research in Mathematics Education 21 (1990), 33-46.

[10] B. Hodges, G. Regehr and D. Martin, Difficulties in recognizing one's own incompetence: Novice physicians who are unskilled and unaware of it, Academic Medicine 76 (2001), 87-89.

[11] E. Hong and L. Kerstensson, Antecedents of state and test anxiety, Contemporary Educational Psychology 27 (2002), 348-367.

[12] M. A. Hudak and D. E. Anderson, Formal operations and learning style predict success in statistics and computer science courses, Teaching of Psychology 17 (1990), 231-234.

[13] J. Kruger and D. Dunning, Unskilled and unaware of it: How difficulties in recognizing one's own incompetence lead to inflated self-assessments, Journal of Personality and Social Psychology 77 (1999), 1121-1134.

[14] S. E. Mason and D. N. Grenier, Introductory psychology and statistics: The relationship between course structure and anxiety, Eastern Psychological Association, 2005, March.

[15] A. J. Onwuegbuzie, Statistics anxiety and the role of self-perceptions, 1 The Journal of Educational Research 93 (2000), 323-330.

[16] W. Pan and M. Tang, Examining the effectiveness of innovative instructional methods on reducing statistics anxiety for graduate students in the social sciences, Journal of Instructional Psychology 31 (2004), 149-159.

[17] W. Pan and M. Tang, Students' perceptions on factors of statistics anxiety and instructional strategies, Journal of Instructional Psychology 32 (2005), 205-214.

[18] J. J. Walsh and G. Ugumba-Agwunobi, Individual differences in statistics anxiety: The roles of perfectionism, procrastination and trait anxiety, Personality and Individual Differences 33 (2002), 239-251.

Susan E. Mason, Department of Psychology, DePaul Hall, PO Box 2208, Niagara University, New York, 14109, USA

e-mail: sem@niagara.edu

Elizabeth M. Reid, School of Computer Science and Mathematics, Hancock Center, Marist College, 3399 North Road, Poughkeepsie, New York, 12601, USA 